\title{
The Practice of Political Online Teaching of Wireless Sensor Network Course based on ZIGBEE
}

\author{
Xiangyang Shu ${ }^{1}$ \\ ${ }^{1}$ Hunan University of information technology, Hunan, China, 410151
}

\begin{abstract}
ZIGBEE technology is based on mature communication standards, and its technology application field is more and more extensive, such as intelligent home appliances, medical health, military reconnaissance, environmental monitoring and other aspects have great development space. With the development of science and technology, information technology, represented by multimedia and network technology, has been widely used in education field. The use of information technology has attracted more and more attention of teachers and students. But the current situation is not ideal for the deep integration of information technology and political teaching. The purpose of this paper is to study the application of wireless sensor network in the political online classroom, to increase the integration of information technology and political education, and to improve the interest of students in political learning. This paper, through the relevant theoretical research, considers the application of WLAN in political classroom, analyzes its advantages and makes teaching process. The shortcomings of traditional wireless sensor network are analyzed and the optimization algorithm is proposed to save energy. In the environment of wireless sensor network deployment, an online teaching platform is built. This paper uses SSH framework technology to realize the functions of the system, and gives the specific introduction of the realization of each function module in the system. Through the system debugging, deployment and implementation, the system successfully completed the course deployment and implementation, which strongly supports the smooth progress of the flipped classroom teaching reform. Finally, through questionnaire and interview, teachers and students have a good attitude towards online teaching platform, the highest satisfaction of the system stability is $100 \%, 86.67 \%$ of the teachers are satisfied with the ease of use of the system operation.
\end{abstract}

\section{Introduction}

Today's era has been a period of rapid economic development driven by information technology. With the further development and evolution of information science and technology, it has gradually penetrated into all aspects of economy and society, bringing a series of technological innovation and changes in related fields [1-2]. The same is true of education and teaching. With the rapid development of educational informatization in China, various multimedia and modern educational technologies are widely used in Classroom Teaching [3-4]. Grasping the relationship between information technology and teachers and students in modern classroom has become an important education topic [5-6].

With the advent of the "Internet plus" education era, many scholars have studied countless online teaching models beyond count [7-8]. For example, MOOCS in Chinese universities is an online teaching project cooperated by the Ministry of education of the people's Republic of China and NETEASE. The platform provides excellent classrooms for university students to learn online; some scholars have also applied the online homework platform to primary school mathematics homework, using the "homework together" online platform to assist teaching, which has improved students' interest in learning, learning enthusiasm and academic performance [10].

Based on the relevant theoretical research, this paper thinks about the application of WLAN in political classroom, analyzes its advantages and formulates the teaching process [11]. This paper analyzes the shortcomings of the traditional wireless sensor network, and proposes the optimization algorithm to save energy consumption, and constructs the online teaching platform in the environment of wireless sensor network deployment. In this paper, through the use of $\mathrm{SSH}$ framework technology to achieve the various functions of the system, gives a specific introduction to the implementation of each function module in the system. After system debugging, deployment and implementation, the system has successfully completed the course deployment and implementation, which strongly supports the smooth progress of flipped Classroom Teaching Reform [12]. 


\section{Related Concepts of Online Teaching Based On ZIGBEE Wireless Sensor Network}

\subsection{Thinking about the Application of Wireless Sensor Network in Online Teaching}

\subsection{1 "Interaction" in Teaching}

In the online teaching of politics, electronic devices are used to support the establishment of wireless sensor network, which is student-centered and focuses on "interaction" and real-time analysis, so as to cultivate students' hands-on experimental ability, active learning ability and cooperative learning ability.

\subsubsection{Advantages of Wireless Sensor Network in Political Online Teaching}

1) Simple operation and convenient application

The application of WLAN in classroom teaching only requires that the classroom is equipped with basic equipment, computers and projectors, and even teachers can bring their own laptops. There is no requirement on whether there is a network in the classroom. If the computer in the classroom cannot access the Internet, the teacher only needs to carry a mobile phone that can access the Internet.

2) Multiple classroom interaction to create a dynamic classroom

The application of WLAN in political teaching breaks through the traditional sense of teacher-student interaction, and adds "interaction between human and environment". In the information environment, it uses network transmission to obtain resources for interaction between human, human and resources, and between resources.

3) Real time transmission to improve students' autonomous learning and cooperative learning ability

In the specific process of teaching, teachers will open the Internet, allowing students to get the information they need through wireless access to the Internet, integrating network information into classroom teaching, greatly enhancing the enthusiasm of students to participate in classroom learning activities, and enhancing students' interest in learning. Because students use their own smart phones, it breaks through the traditional rule that teachers forbid students to use mobile phones in class, increases the trust between teachers and students, and promotes students' autonomous learning from another level.

4) Diversified evaluation methods

The application of wireless sensor network in politics teaching can give full play to the role of formative assessment. In the process of teaching, a research problem is established. Teachers and students work together in groups to study. Under the guidance of teachers, students study independently. The research results are transmitted in real time by students themselves. Through the real-time transmission of wireless network, the research situation of each group can be seen directly. Students in the group can explain themselves or comment on other groups, every comment is students' independent thinking, with independent, personalized views.

5) Multimedia network technology shared by teachers and students

The application of WLAN in chemistry teaching can embody the deep integration of information technology and subject teaching, and realize teachers and students sharing multimedia for teaching.

\subsection{Energy Optimized ZIGBEE Routing Algorithm}

\subsubsection{Limit the Broadcasting Range of RREQ}

Short path naturally saves energy. ZIGBEE routing protocol combines the advantages of cluster tree and AODVJR. AODVJR can find a better path than cluster tree algorithm, but if the path found is longer than the path selected by cluster tree algorithm, it should reduce the path length to save energy. If the $\mathrm{RN}+$ node is faced with the choice of how to forward data, it requests other nodes to help forward RREQ by routing broadcast to the neighbor node, so it can find the best path to the destination node; therefore, the measure is to limit the transmission range of RREQ packets to be less than the length of the path found by the node according to the cluster tree algorithm. In this way, the removed transmission not only has a weak impact on the network performance, but also can save a lot of energy.

\subsubsection{Implementation Method}

Generally, the maximum network depth of cluster tree routing in ZIGBEE network is LM, and the maximum path is $2 L_{-} \mathrm{m}$; If the maximum broadcasting depth of RREQ is $2 L_{-} m$. The propagation path length of RREQ is $2 \mathrm{~L}_{-} \mathrm{M}$, the node discards it. This method sets the broadcasting depth of RREQ, in order to reduce the number of times of RREQ forwarding, so that the total number of times of forwarding RREQ is correspondingly reduced, thus reducing the energy consumption of the network.

\subsubsection{Judge the Relationship between the $R N+$ Node and the Destination Node}

\section{1) Judge node relationship}

After receiving RREQ, any node obtains whether the destination node is its own child node by formula. If the point is its own child node, its parent node will not continue to forward; On the contrary, if not, it will not be sent to its own children, because it is obviously meaningless. If the $\mathrm{RN}+$ node can judge the relationship between the node and the destination node when forwarding, it can determine where the data should be transmitted.

2) Implementation method

Add a flag to RREQ to identify the relationship between the node and the destination node. 


\subsubsection{Optimized Routing Method for Balancing Node Energy Consumption}

When selecting a route, the remaining energy of the node should also be used as an important basis to evaluate the energy consumption of the route. The node with less battery power balance is less involved in routing forwarding, and the node with more battery power balance is more involved in routing forwarding, so as to balance the remaining battery power of the node. The node with more residual energy has to undertake more routing and forwarding functions, so it is more likely to use this node in forwarding data, and the routing overhead of this node is smaller. Using le to represent the residual energy of node, if node has a more descendants, it proves that the node consumes more energy. Of course, it indicates that the node is also more important, so the probability of using the node will be smaller. The function can determine the number of child nodes, so the higher the value of is, the higher the routing cost of the node is, and the smaller the value of Le is. If the routing cost of the central coordinator is zero, and cost means that a node has cost, the above relationship can be written in the mathematical expression:

Cost $=\left\{\begin{array}{l}0 \quad \text { The node is the central coordinator } \\ m \cdot \frac{C \operatorname{sikip}(d)}{L E} \text { Nodes are others, } \mathrm{M} \text { is coefficient }\end{array}\right.$

Therefore, there are:

$$
\mathrm{LE}=\mathrm{E} \cdot \mathrm{n}(2)
$$

Where e is the initial battery energy of the node battery; $\mathrm{N}$ is the percentage of the remaining battery energy in the initial energy.

\section{Design and Implementation of Political Online Teaching System}

\subsection{Implementation of Online Teaching Platform}

\subsubsection{Implementation of SSH Framework}

1) Configuration of web.xml

The main configuration contents of web.xml configuration file include: default welcome page, naming or customizing URL, customizing initialization parameters, setting exception handling page, setting filter, setting listener, setting session timeout, etc.

2) Configuration of struts-config.xml

Struts-config.xml is an important configuration file of struts, which includes data source, static form bean, dynamic form bean, action and mapping, resource file, plug-in, etc.

3) Configuration of spring-web.xml, spring-service. $\mathrm{xml}$ and spring dao.xml

In spring-web.xml, configure the action component for spring container, and inject the business logic proxy component called by action through configuration dependency. In spring-service.xml, the business logic component is mainly configured in the spring container, and the dependency of database access agent component is injected into the business logic component through configuration. The configuration of spring-dao.xml mainly includes the configuration of data source and database access proxy object.

\subsubsection{Implementation of the Business Function of Teachers' Application for Class Opening}

The course manager should first log in as a teacher to the system homepage teacher.jsp, click apply to open the course application page courseapply.jsp, enter the basic information of the course to be applied, enter the basic information of the course application, click upload the pre-recorded course video example, and submit the course application.

\subsubsection{The Realization of the Course Opening Audit Business Function of Educational Administration Management Personnel}

After the educational administrator logs in to the system, click a course option to be audited, log in to the course audit page courseverify.jsp page, and the page displays the course information and course application information of the course to be audited, educational administration and reading audit, and watch the course video demo online. Educational administrators input audit opinions and submit them to the system.

\subsubsection{Realization of Teaching Material Management Business Function}

After the teacher logs in the course space page, click teaching material management to enter the teaching material management page materialmanage.jsp, which displays all the knowledge nodes directory tree and teaching materials under the node. Teachers can select the directory node and click upload teaching materials to upload the teaching materials under the corresponding node; select node material, select delete material and delete teaching material; select teaching materials, click the mobile location, change the knowledge node ownership of teaching materials.

\subsection{System Implementation}

\subsubsection{System Implementation Process}

1) System Test and Commissioning

In the process of coding, the programmer tests the unit constantly in the coding process to ensure that the code unit can realize the requirements of the unit module correctly; in the incremental development of each function module, the system is integrated effectively according to the requirements by alternating integration test and unit test; after the system function is completed, the system is well confirmed and tested, which is mainly based on the description of the overall function requirements of the system; finally, after the system is deployed to the production environment, several tests are 
carried out for the sub functional requirements, including: security test, pressure test, etc.

2) System Deployment and Migration

Under the cooperation of the academic affairs office and information center of the college, the system is successfully deployed and implemented in the campus intranet, and runs in parallel with the original prototype system. After the system is deployed, the basic information of the system is initialized. According to the staffing and process requirements, several accounts are established and the corresponding permissions are assigned. The data, teaching materials, account information and so on in several courses running under the original prototype system are imported into the new system for testing and operation, with minor debugging and modification.

\subsubsection{System Deployment and Operation}

1) System Deployment Environment

Campus IT infrastructure environment: the campus generally adopts Gigabit backbone network and supporting equipment, and the main learning place is covered by WIFI, and the student dormitory provides convenient and high-speed access to the network. The college computing center provides advanced server cluster, adopts VMware virtualization technology, and supports various management applications of the college.

2) Application Deployment Environment

On the basis of virtualization, the system deployed application services to a virtual web application server, and connected the virtual database server through virtual network to provide database access services.

\section{Evaluation and Feedback}

The classroom group related to flipped classroom teaching conducted feedback survey on the effect of flipped classroom teaching and support platform by means of questionnaire survey. The survey information mainly includes two parts: flipped classroom and teaching platform support. Here is the main survey information about the platform.

The summary of 15 questionnaires from teachers about teaching platform is shown in Table 1.

Table 1. Summary of questionnaire survey on implementation effect feedback teachers

\begin{tabular}{|c|c|c|c|c|c|c|}
\hline $\begin{array}{c}\text { Serial } \\
\text { number }\end{array}$ & research questions & very good & preferably & commonly & Poor & bad \\
\hline 1 & $\begin{array}{l}\text { Is the function of the system to support flipped } \\
\text { classroom perfect? }\end{array}$ & 10 & 4 & 1 & 0 & 0 \\
\hline 2 & How compatible is the system with teaching materials? & 5 & 8 & 2 & 0 & 0 \\
\hline 3 & $\begin{array}{l}\text { What's the response speed of school source intranet } \\
\text { system and video playback? }\end{array}$ & 15 & 0 & 0 & 0 & 0 \\
\hline 4 & $\begin{array}{l}\text { How fast does the system respond to the off campus } \\
\text { broadband network environment? }\end{array}$ & 0 & 3 & 6 & 2 & 1 \\
\hline 5 & How easy is the system operation? & 13 & 2 & 0 & 0 & 0 \\
\hline 6 & $\begin{array}{l}\text { Are you satisfied with the implementation of the } \\
\text { application process? }\end{array}$ & 7 & 0 & 0 & 0 & 0 \\
\hline 7 & $\begin{array}{l}\text { Are you satisfied with the implementation of online test } \\
\text { function? }\end{array}$ & 8 & 5 & 2 & 0 & 0 \\
\hline 8 & $\begin{array}{l}\text { Are you satisfied with the realization of teaching } \\
\text { material management function? }\end{array}$ & 15 & 0 & 0 & 0 & 0 \\
\hline
\end{tabular}

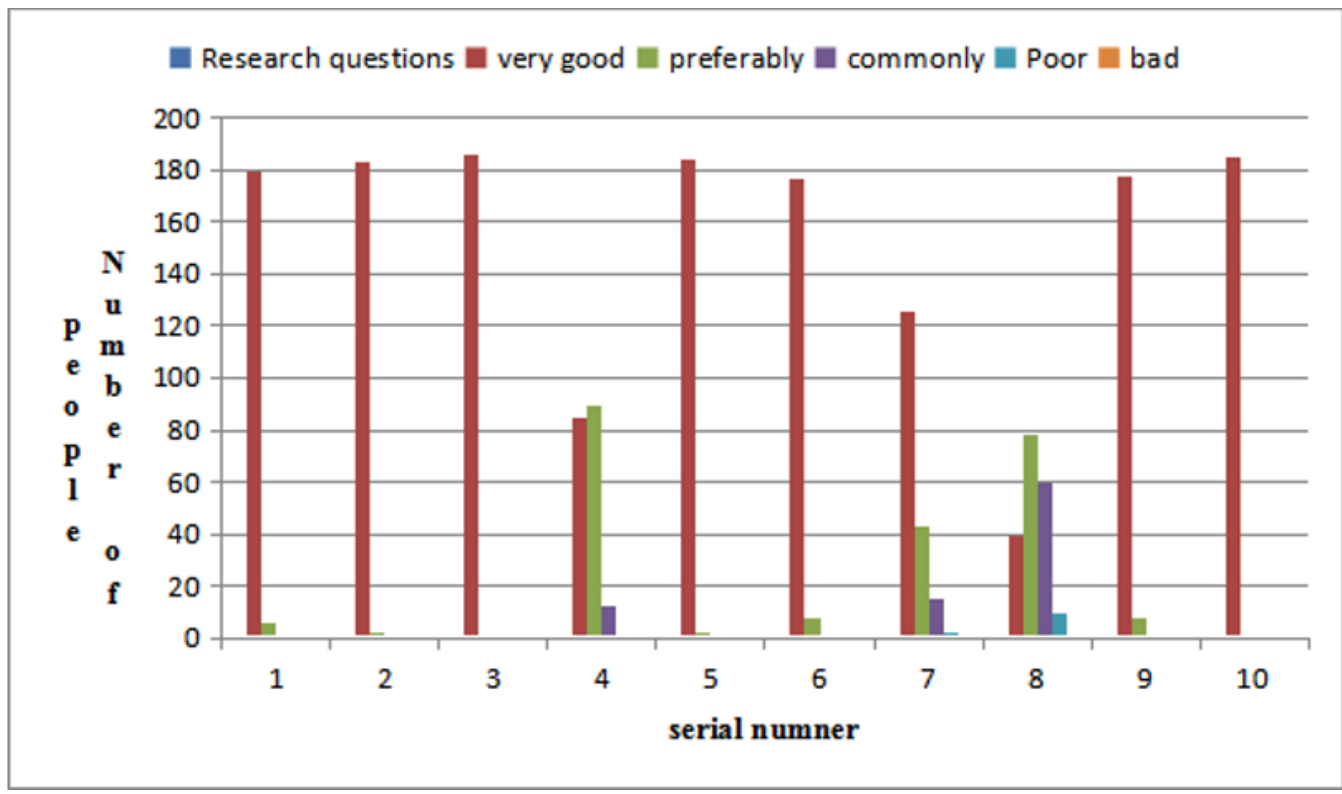

Figure 1. Summary of questionnaire survey on implementation effect feedback teachers 
According to the survey and summary in Figure 1, the system platform has played a supporting role in the teaching reform of flipped classroom. Teachers give a high evaluation on the basic functions of the system, such as the ease of operation and the management of teaching materials. But at the same time, teachers' satisfaction with the realization of online testing function is low, and individual teachers' response speed is not ideal when using the system outside school.

The feedback of 186 questionnaires from students of flipped classroom reform course is shown in Table 2:

Table 2. Summary of student questionnaire on implementation effect feedback

\begin{tabular}{|c|c|c|c|c|c|c|}
\hline $\begin{array}{c}\text { Serial } \\
\text { number }\end{array}$ & Research questions & very good & preferably & commonly & Poor & bad \\
\hline 1 & $\begin{array}{l}\text { The convenience of acquiring knowledge needed by } \\
\text { flipped classroom teaching from the platform }\end{array}$ & 179 & 6 & 1 & 0 & 0 \\
\hline 2 & The usability of teaching platform & 183 & 2 & 0 & 0 & 0 \\
\hline 3 & system stability & 186 & 0 & 0 & 0 & 0 \\
\hline 4 & Online test function ease of use & 85 & 89 & 12 & 0 & 0 \\
\hline 5 & Ease of use of online question answering function & 184 & 2 & 0 & 0 & 0 \\
\hline 6 & $\begin{array}{c}\text { The role of flipped classroom teaching mode in } \\
\text { improving students' ability }\end{array}$ & 177 & 8 & 1 & 0 & 0 \\
\hline 7 & The quality of teaching material and teaching video & 126 & 43 & 15 & 2 & 0 \\
\hline 8 & The interest of teaching video & 39 & 78 & 60 & 9 & 0 \\
\hline 9 & $\begin{array}{c}\text { Compared with the traditional classroom, flipped } \\
\text { classroom teaching mode is more interesting }\end{array}$ & 178 & 8 & 0 & 0 & 0 \\
\hline 10 & $\begin{array}{l}\text { How do you feel about promoting flipped classroom } \\
\text { mode through teaching platform? }\end{array}$ & 185 & 1 & 0 & 0 & 0 \\
\hline
\end{tabular}

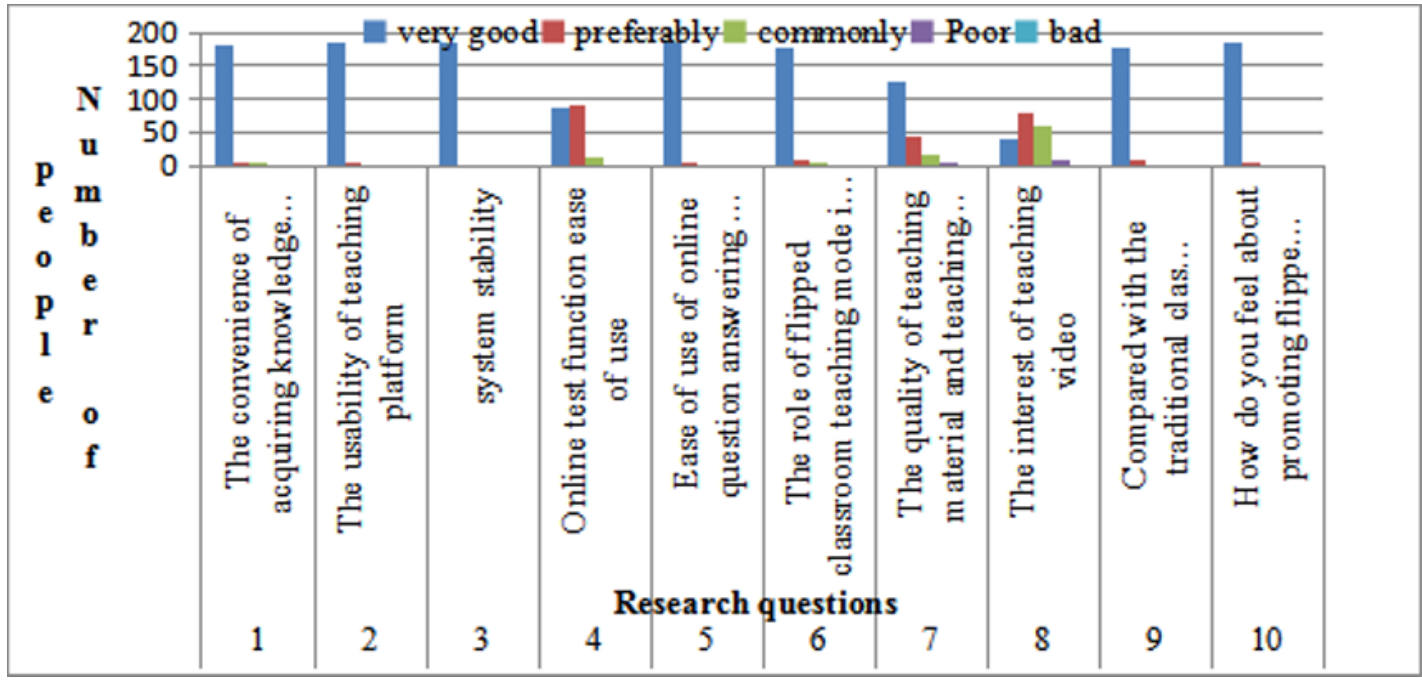

Figure 2. Summary of student questionnaire on implementation effect feedback

\section{Conclusion}

This question, which is closely combined with the actual needs of higher education reform, analyzes, designs and implements an online teaching system based on flipped classroom teaching mode. After test feedback, the system realizes the predetermined functions, and better supports the practice of flipped classroom teaching reform of the subject group, it has made contributions to the exploration practice of the deep integration of information technology and higher education reform.

\section{References}

1. Gregory S , Bannister-Tyrrell M . Digital learner presence and online teaching tools: higher cognitive requirements of online learners for effective learning[J]. Research \& Practice in Technology Enhanced Learning, 2017, 12(1):18.

2. Du Ping. A study on the influencing factors of the effectiveness of online teaching video presentation\% [J]. Journal of Wuhan Polytechnic, 2017, 016 (002): 81-83

3. Adnan, M. , Kaleliolu, F. , \& Y Gülbahar. (2017). Assessment of a multinational online faculty development program on online teaching: reflections of candidate e-tutors. Turkish Online Journal of Distance Education, 18(1), 22-38.

4. Rhode J , Richter S , Miller $\mathrm{T}$. Designing Personalized Online Teaching Professional Development through Self-Assessment.[J]. TechTrends, 2017, 61(5):1-8. 
5. Wang L , Wang Z . Research on the System Design and Development of Online Teaching Platform based on ASP.NET[J]. Boletin Tecnico/technical Bulletin, 2017, 55(7):539-546.

6. Callo E C , Yazon A D . Exploring the Factors Influencing the Readiness of Faculty and Students on Online Teaching and Learning as an Alternative Delivery Mode for the New Normal[J]. Universal Journal of Educational Research, 2020, 8(8):3509-3518.

7. Salih K , Rashid C A, Salih H A, et al. The Role of Online Teaching Tools on the Perception of the Students during the Lockdown of Covid-19[J]. International Journal of Social Sciences and Educational Studies, 2020, 7(3):178-190.

8. Liu P, Wang $\mathrm{X}$, Teng $\mathrm{F}$. Online teaching quality evaluation based on multi-granularity probabilistic linguistic term sets[J]. Journal of Intelligent and Fuzzy Systems, 2021(2):1-20.

9. Bhat, S. , et al. "Constructive Methodologies to Overcome the Technological Barriers in Online Teaching-Learning Process." Journal of Engineering Education Transformations 34(2021):707.

10. Hoesel L V, Nieberg $\mathrm{T}$, Jian $\mathrm{W}$, et al. Prolonging the lifetime of wireless sensor networks by cross-layer interaction[J]. IEEE Wireless Communications, 2017, 11(6):78-86.

11. Chen Z, Liu A, Li Z , et al. Energy-Efficient Broadcasting Scheme for Smart Industrial Wireless Sensor Networks[J]. Mobile Information Systems,2017,(2017-01-23), 2017, 2017(12):1-17.

12. Luo J , Hu J , D Wu, et al. Opportunistic Routing Algorithm for Relay Node Selection in Wireless Sensor Networks[J]. IEEE Transactions on Industrial Informatics, 2017, 11(1):112-121. 